\title{
The Brainstem Oscillator for Whisking and the Case for Breathing as the Master Clock for Orofacial Motor Actions
}

\author{
David Kleinfeld ${ }^{1,2}$ Jeffrey D. Moore, ${ }^{1}$ Fan Wang, ${ }^{3}$ and Martin Deschênes ${ }^{4}$ \\ ${ }^{1}$ Department of Physics, University of California San Diego, La Jolla, California 92093 \\ ${ }^{2}$ Section of Neurobiology, University of California San Diego, La Jolla, California 92093 \\ ${ }^{3}$ Department of Neurobiology, Duke University Medical Center, Durham, North Carolina 27710 \\ ${ }^{4}$ Department of Psychiatry and Neuroscience, Laval University, Quebec City, Quebec GIJ 2G3, Canada \\ Correspondence: dk@physics.ucsd.edu
}

\begin{abstract}
Whisking and sniffing are predominant aspects of exploratory behavior in rodents. We review evidence that these motor rhythms are coordinated by the respiratory patterning circuitry in the ventral medulla. A recently described region in the intermediate reticular zone of the medulla functions as an autonomous whisking oscillator, whose neuronal output is reset upon each breath by input from the pre-Bötzinger complex. Based on similarities between this neuronal circuit architecture and that of other orofacial behaviors, we propose that the pre-Bötzinger complex, which projects broadly to premotor regions throughout the intermediate reticular zone of the medulla, functions as a master clock to coordinate multiple orofacial actions involved in exploratory and ingestive behaviors. We then extend the analysis of whisking to the relatively slow control of the midpoint of the whisk. We conjecture, in a manner consistent with breathing as the "master clock" for all orofacial behaviors, that slow control optimizes the position of sensors whereas the breathing rhythm provides a means to perceptually bind the inputs from different orofacial modalities.
\end{abstract}

A postulate from the neuroethology movement is the presence of a hierarchical control structure for motor acts that is orchestrated by the nervous system (Weiss 1941; Tinbergen 1951). At the base of this hierarchy are individual motor "actions." For example, orofacial actions that comprise sensory exploration would correspond to a sniff, a twitch of the nose, a lick, a whisk, or a turn of the head. These actions are coordinated in nested groups to form more complex "behaviors." The nature of the interactions among the neuronal circuits that generate these actions and coordinate their output is a foundational topic in computational neuroscience. One question, which motivates the present work, concerns the possibility of using a master clock as a means to organize motor actions into behaviors. The use of such a clock could provide a computationally simple mechanism to avoid antagonistic movements and to adhere to biomechanical constraints. Presumably, the clock could function as part of a larger circuit that involves interactions between motor and premotor neuronal centers, as well as environmental and proprioceptive feedback signals. For the case of exploratory movements, the use of a common clock to actively sample the sensory environment could simplify the problem of binding inputs arising from different modalities (e.g., smell, touch, and taste) (Kleinfeld et al. 2014).

The notion of a master clock is implicit in the pioneering work of Welker (1964), published a half century ago, who observed that movements of the nose, the head, and the vibrissae of rodents appear to be coherent with rapid breathing, or sniffing. Together, these three actions are hypothesized to synchronize with the breathing cycle to form a stereotyped exploratory behavior that rodents use to rhythmically sample their surrounding olfactory and tactile environments (Fig. 1). A parsimonious conclusion is that the breathing cycle may be the master clock at the root of all rhythmic orofacial behaviors.

Here we summarize our recent work on the neuronal circuitry that controls rhythmic exploratory whisking by rats (Moore et al. 2013); this work provides evidence that whisking is subsumed by the breathing rhythm. Our summary is followed by a presentation of two threads of subsequent, and ongoing, inquiry. Motivated by anatomical similarities between this newly discovered brainstem whisking circuit and those circuits thought to control the tongue and jaw, the first thread bears directly on the issue of a master clock and concerns the potential role of breathing in the synchronization of other motor actions. The second thread addresses the mechanistic basis for controlling the slowly varying amplitude and position of whisking, which we propose may be organized similarly to the control of body posture.

It is instructive to begin with an overview of the motor plant for whisking. A Manhattan-like grid of follicles is embedded within the mystacial pad (Fig. 2), which forms the cheek. Intrinsic muscles wrap around individual vibrissa follicles and are only partially inserted into the skin (Fig. 2A). These muscles resemble slings that embrace 


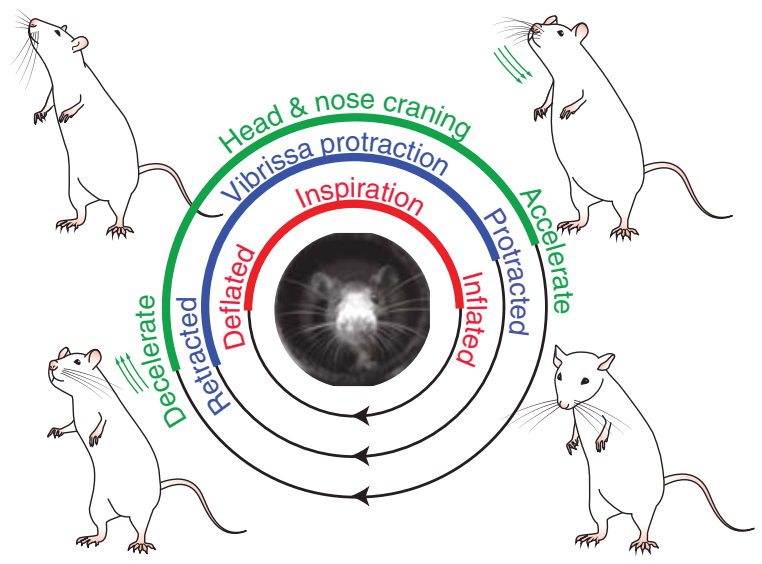

Figure 1. A cycle of exploratory behavior locked to sniffing. Three motor actions, whisking, head bobbing, and nose twitching, are linked to a fourth, sniffing, during orofacial exploration. (Abstracted from the claims of Welker 1964.)

the lower half of the follicle, and they are anchored to each of two adjacent follicles of the same row (Fig. 2B; Dörfl 1982; Wineski 1985). In addition, five superficial extrinsic muscles are inserted into either the plate or the skin of the pad, between the rows of follicles. These muscles include $m$. nasalis as a protractor and $m$. nasolabialis and m. maxillolabialis as retractors (Fig. 2C). Simultaneous measurements of the electromyogram (EMG) from the intrinsic and extrinsic muscles indicate the presence of three phases of muscle contraction during the whisking cycle (Fig. 2D), with different phases for the extrinsic protractor, intrinsic protractor, and extrinsic retractor muscles (Hill et al. 2008).

To verify our understanding of the muscular control of whisking, we constructed a mechanical model of the motor plant to predict the motion of the vibrissae and the mystacial pad from the measured EMGs of the intrinsic and different extrinsic muscles (Fig. 2D; Hill et al. 2008). The anatomy of the musculature, including attachment points in the skin and plate together with measurements of the viscoelastic restoring forces, provides the data that inform the model (Fig. 2E; Hill et al. 2008; Simony et al. 2010). For whisking while sniffing, we find excellent agreement between the calculated and measured motion of both the vibrissae and the pad (Fig. 2F). This implies the presence of a multiphase rhythmic pattern generator. For concreteness, we focus this presentation on the rhythm that dominates protraction through direct drive of the intrinsic muscles. Such a presentation is analogous to much of the literature that describes the motor control of breathing, which also consists of three phases of neuronal activity, yet the inspiratory phase can be driven by a single oscillator circuit (Smith et al. 2009).

Concurrent measurements of breathing and whisking in head-restrained rats reveal key aspects of their coordination (Moore et al. 2013; Ranade et al. 2013), and extend Welker's initial descriptions (Fig. 3). First, breathing over a wide range of frequencies can occur without substantial whisking (Fig. 3A). To determine whether whisking can also occur without breathing, a puff of ammonia was applied to the snout to inactivate the central inspiratory drive (Lawson et al. 1991) and temporarily inhibit respiration. Critically, rats can whisk during such a disruption in breathing (Fig. 3B). These data imply that there are separate, or separable, oscillator circuits for breathing and whisking.

Sniffing is always accompanied by a one-to-one relation with whisking (Fig. 3A,B), as first noted by Welker (1964). Yet basal breathing, which is two to five times slower than whisking, is accompanied by two forms of whisks: those that are coincident with an inspiration, which we denote "inspiratory-locked whisks," and those that occur between successive breaths and successively diminish in amplitude, which we denote "intervening whisks" (Fig. 3C,D). The "intervening whisks" are incommensurate with breathing. These data, with further support from phase-response curves (Moore et al. 2013), imply that the oscillator circuit for breathing resets the phase of the oscillator for whisking.

Where is the pattern generator for this fast, rhythmic vibrissa motion? One possibility is that rapid whisking is generated by a disynaptic feedback loop in the brainstem (Nguyen and Kleinfeld 2005; Deutsch et al. 2012; Matthews et al. 2014). That is, sensory signals generated by the motion of the vibrissa could drive the facial motoneurons, which in turn would regenerate a sensory signal, and so on. However, lesion of the vibrissa sensory nerve (i.e., the infraorbial branch of the trigeminal) has minimal effect on whisking (Welker 1964; Gao et al. 2001; Berg and Kleinfeld 2003) and thus disproves this hypothesis. Further, lesion of any of a large number of midbrain and forebrain nuclei only minimally disrupts whisking (Welker 1964; Lovick 1972; Semba and Komisaruk 1984). These observations lead to the alternative hypothesis that there is an independent oscillator that drives whisking and is located in the brainstem. But where? Given the close phase relationship between whisking and breathing, the neighborhood of the ventral respiratory column in the medulla (Smith et al. 2009) is a plausible suspect. A role for breathing in the control of whisking is also suggested by the shared facial musculature between the two behaviors (Sherrey and Megirian 1977; Haidarliu et al. 2012). We thus directed our search near the location of the pre-Bötzinger complex, which was first showed by Feldman and colleagues (Smith et al. 1991; Tan et al. 2008) to generate the inspiratory breathing rhythm.

The close, one-to-one relationship between sniffing and whisking makes it difficult to discriminate between potential breathing and whisking neuronal centers (Fig $3 \mathrm{~A})$. However, the difference in the frequency of basal respiration versus whisking provides a behavioral signature for such a discrimination (Fig. 3C,D; Moore et al. 2013). We recorded unit spiking activity within the preBötzinger complex as well as in the rostral ventral respiratory group in head-fixed awake rats. As expected, spiking occurred in phase with inspiration and with vibrissa protraction during inspiratory-locked whisks (Fig. $3 \mathrm{C}$ and red dots in Fig. 3E). Critically, the spiking activity 


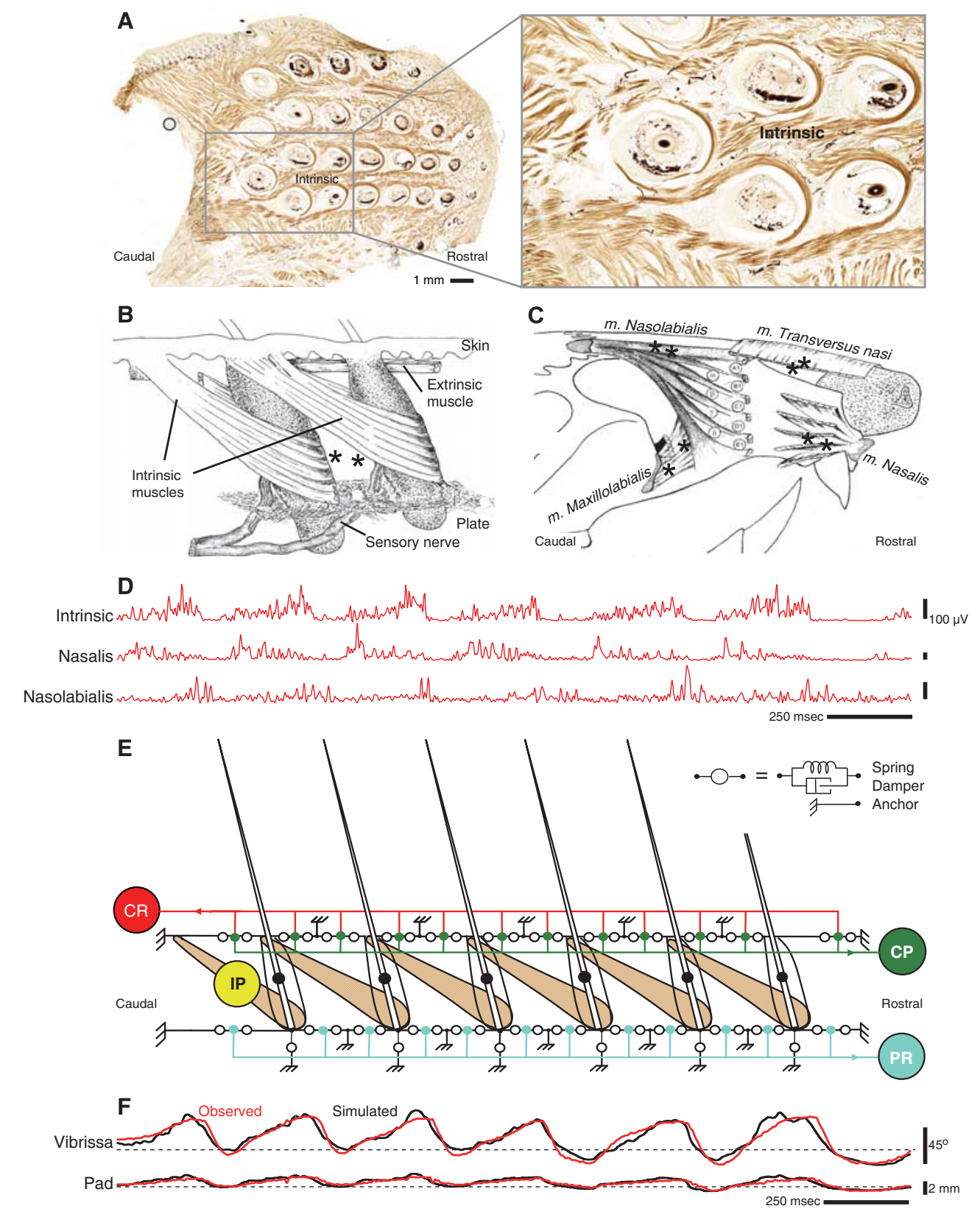

Figure 2. The nature of the motor plant for whisking. (A) A tangential slice containing a whole set of intrinsic muscles that form slings about the follicles that house the vibrissae. Most of the muscle slings are only partially represented in this plane. $(B)$ Drawing of intrinsic musculature and follicular anatomy. The intrinsic muscles join adjacent follicles of a single row. Each muscle attaches medially and laterally to the superior part of the caudal follicle while forming a sling around the lower third of the rostral follicle. The skin on the outside and the plate on the inside provide a passive restoring force. Superficial extrinsic muscles run just below the skin. Asterisks indicate the approximate locations of the exposed tips of EMG microwires (Hill et al. 2008). (Adapted, with permission, from Dörfl 1982, (C) Wiley.) (C) Drawing of extrinsic musculature. Four extrinsic muscles invade the mystacial pad while maintaining external attachment points. The protractor $m$. nasalis attaches rostral to the pad at the nasal septum and runs under the skin as it extends caudally. The retractor $m$. nasolabialis attaches dorsal-caudal to the pad and runs superficially below the skin. The retractor $m$. maxillolabialis attaches ventral-caudal to the pad and fuses with the fibers of $m$. nasolabialis as they invade the pad. m. transversus nasi lies transverse to the snout and runs superficially through the pad. The recording sites for each muscle are indicated by asterisks. (Adapted from Dörfl 1982.) (D) Muscle activity from head-restrained rats. Electromyogram signals are abbreviated as INT (intrinsic muscles), NA ( $m$. nasalis), NL ( $m$. nasolabialis). The signals are high-pass filtered, full-wave rectified, and low-pass filtered. (Adapted from Hill et al. 2008.) (E) Schematic of a biomechanical model that represents one row of vibrissae in the maxillary compartment of the rat mystacial pad in resting position. Intrinsic whisker protractors (IP) represent intrinsic muscles. The protractor (CP) of the mystacial pad represents the Pars media inferior of the m. nasalis extrinsic muscle, which attached to the skin. The retractor (CR) of the mystacial pad represents the m. maxillolabialis and $m$. nasolabialis extrinsic muscles, which also attach to the skin. The whisker retractor (PR) represents the Pares maxillares superficialis and profunda of the m. nasalis extrinsic muscle, which attach to the plate. Green dots in the skin and blue dots in the plate rows represent attachment sites of the extrinsic muscles. Large black dots represent the centers of mass of the vibrissae. Empty circles represent springs coupled with dampers that symbolize the elasticity of the tissue. Anchors represent nonelastic sites in the mystacial pad. (Adapted from Haidarliu et al. 2010, after Simony et al. 2010 and Hill et al. 2008.) (F) Vibrissa and mystacial pad motion from head-restrained rats recorded concurrently with the EMG data of $D$. The black curve was calculated from a reduced model of the motor plant using the data of $D$ as the sole input. (Adapted from Hill et al. 2008.) 
A

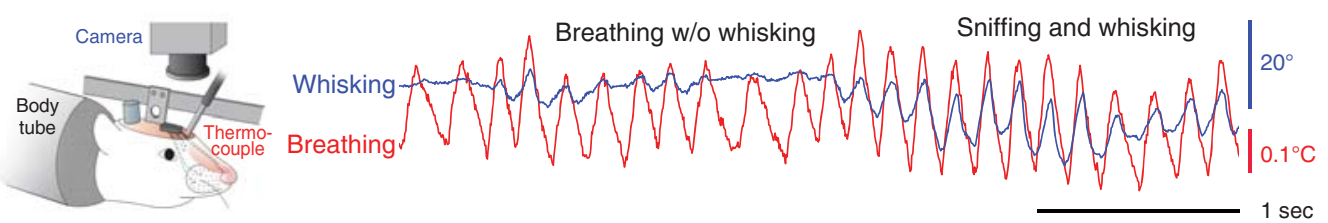

B

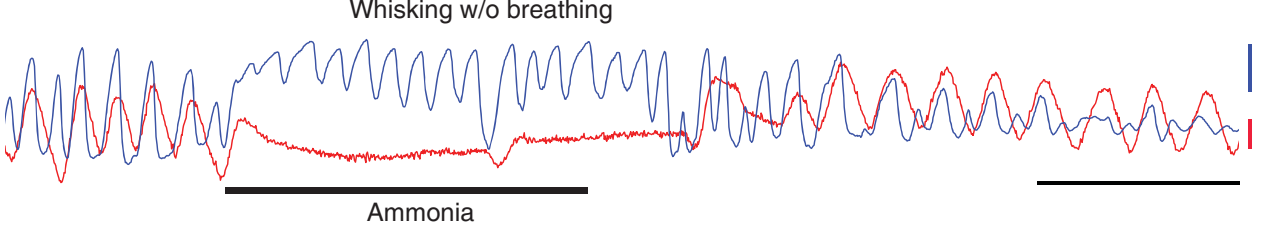

C Intervening whisks

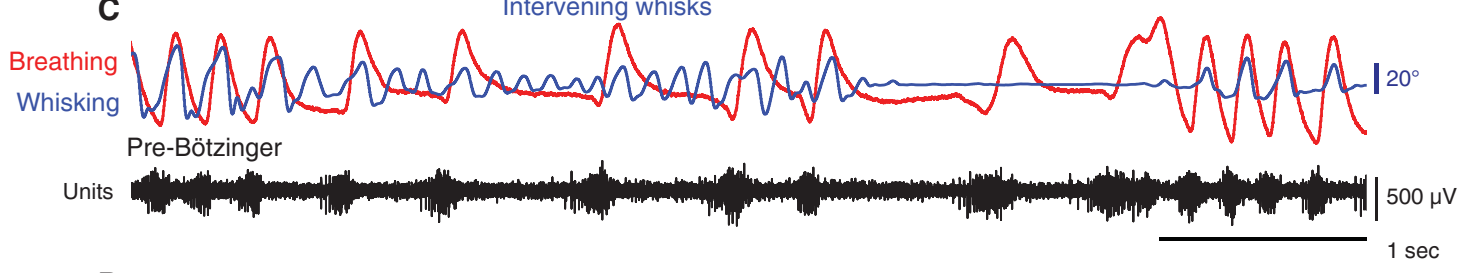

D

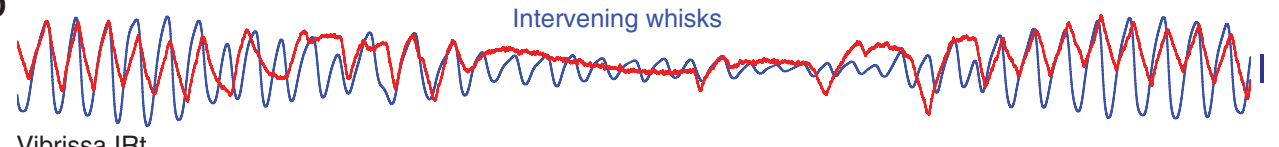

Vibrissa IRt

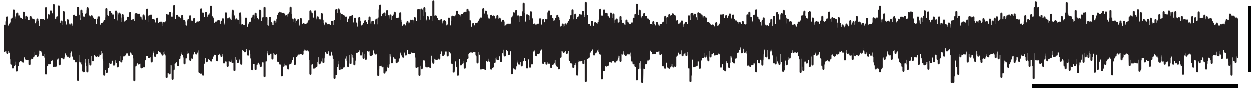

E
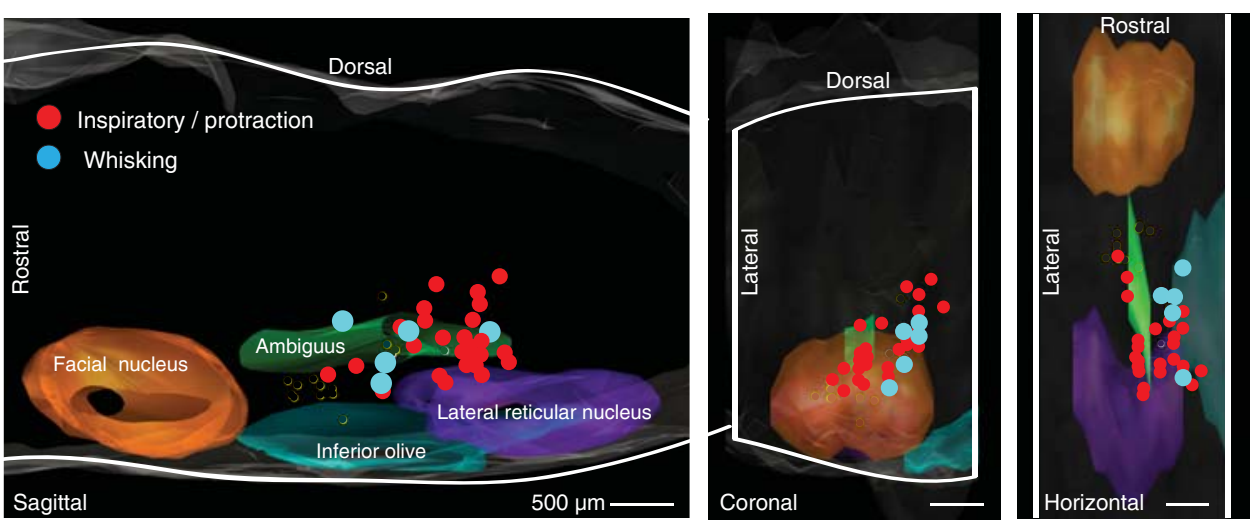

Figure 3. Simultaneous measurements of vibrissa angular position (blue) and breathing (red) in head-fixed rats. $(A)$ Measurement showing epochs of breathing (red) without whisking (blue) and synchronous sniffing and whisking in a head-fixed rat. Insert is a schematic for simultaneous measurements of vibrissa angular position through videography and breathing through the change in temperature of a thermocouple connected to a tube inserted into the nasal passage. $(B)$ Measurement showing an epoch of whisking without breathing, where inspiration was halted by introduction of ammonia into the air mixture. $(C)$ Measurement showing breathing with intervening whisks between inspirations, along with concurrent recordings of multiunit activity (black) in the pre-Bötzinger complex. $(D)$ Measurement showing breathing with intervening whisks between inspirations, along with concurrent recordings of multiunit activity (black) in the vibrissa zone of the intermediate reticular formation. $(E)$ The recording sites for all data imposed on a three-dimensional reconstruction of the medulla. Whisking units (blue) are located in the IRt dorsomedial to inspiratory units (red) in the pre-Bötzinger complex. (Adapted from Moore et al. 2013.)

did not track the intervening whisks. In contrast, we located a subset of units in the intermediate band of the reticular formation (IRt) whose spiking was synchronous with the protraction of both inspiratory-locked and intervening whisks (Fig. 3D and blue dots in Fig. 3E). These units are potential premotor inputs to the motoneurons that drive the intrinsic muscles that protract the vibrissae
(Fig. 2A,B). They are located in the ventral part of the IRt, medial to the ambiguus nucleus and immediately dorsomedial to the pre-Bötzinger complex. We denote this new region the vibrissa zone of the IRt (vIRt) and refer to units in this region as "whisking units."

To show the role of the vIRt in the generation of whisking, we address the necessity and sufficiency of this re- 
gion for rhythmic vibrissa protraction. In support of necessity, we observe that small lesions of the vIRt abolish whisking on the ipsilateral side of the lesion, whereas whisking persists on the contralateral side (Fig. 4A). Off-site lesions, on the other hand, have minimal effects on whisking (Fig. 4B). Sufficiency of the vIRt for rhythmic motion was assessed by activation of this region through microinjection of the glutamate receptor agonist kainic acid in the vicinity of the vIRt. We observe prolonged rhythmic vibrissa movements, at normal whisking frequencies (Carvell and Simons 1990; Berg and Kleinfeld 2003), for injections in the lightly anesthetized rat (Fig. 4C) and mouse (Moore et al. 2014a). The frequency of whisking that is induced by kainic acid is observed to decrease over time, whereas the frequency of basal breathing remains at a constant rate. These data imply that the chemical activation is sufficiently strong to temporally unlock rhythmic vibrissa protraction from breathing.

The ability to induce whisking in an immobile animal through kainic acid microinjection provides a means to stably record from units whose firing times are coherent with rhythmic protraction. We identified neuronal units that spike in synchrony with protraction, as in the case of the units identified during intervening whisks in the behaving animal (Fig. 3D), as well as units that spike in antiphase (Fig. 4D). This finding is suggestive of a rhythm that results from local network dynamics as opposed to coupled single-cell oscillators (Getting 1989; Kleinfeld and Sompolinsky 1989).

The behavioral data (Fig. 3) imply that neurons in the pre-Bötzinger complex reset an oscillatory network of whisking units in the vIRt that initiate protraction of the vibrissae concurrent with each inspiration. What is the nature of the connectivity from the pre-Bötzinger complex to the vIRt? We assessed the underlying connectivity for this action by tract tracing methods (Fig. 5A; Moore et al. 2013). Injections of an anterograde tracer into the pre-Bötzinger complex, identified by the phase relation of units relative to breathing (Fig. 5B), led to dense anterograde labeling of terminals in the same vIRt region where we observed whisking units and where lesions extinguished ipsilateral whisking (Fig. 5C). These results support a direct connection from the pre-Bötzinger complex to the vIRt. In addition, injection of an anterograde tracer into the region of the vIRt does not lead to discernable labeling in the pre-Bötzinger complex (M Deschênes, unpubl.). These data imply that there is only unilateral

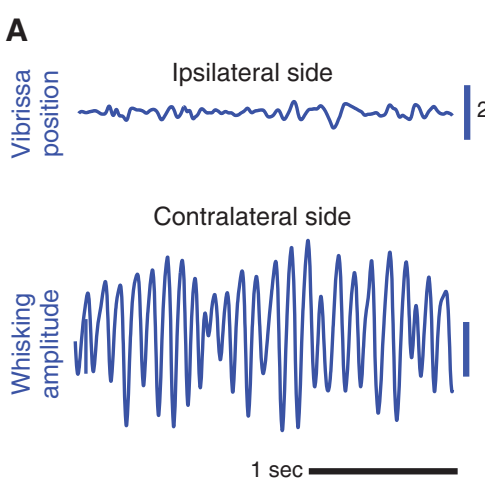

C
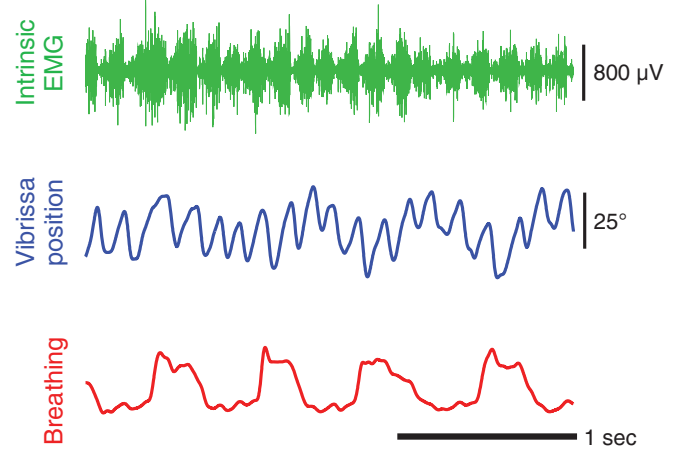

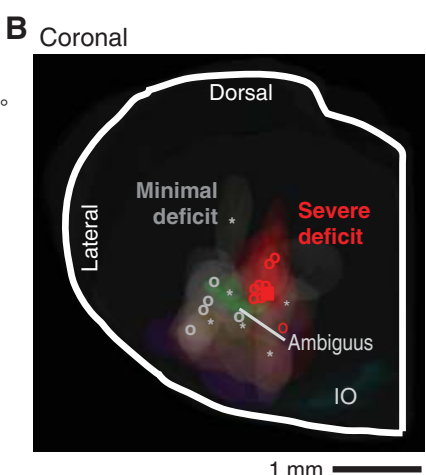

Horizontal

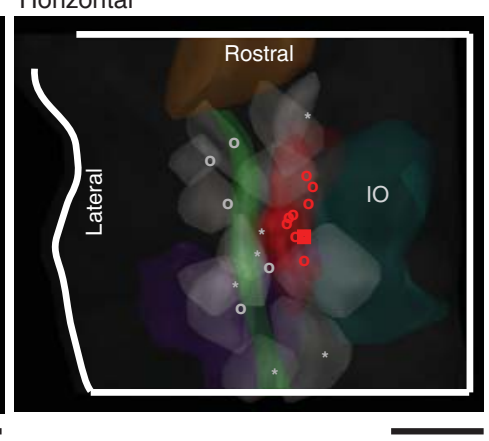

D

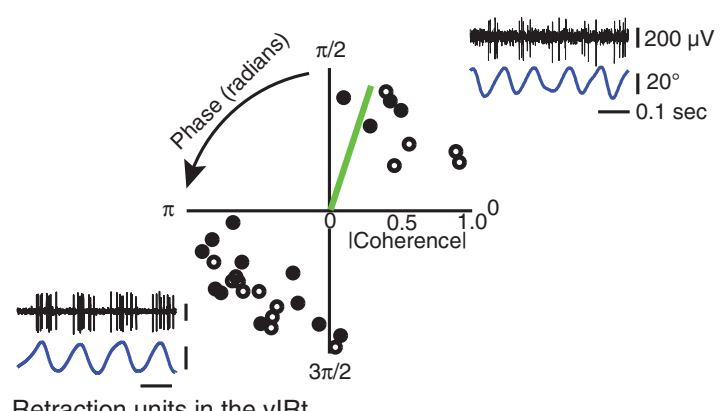

Retraction units in the vIRt

Figure 4. Necessity and sufficiency of the vIRt as the rhythm generator for whisking. Lesion of the vIRt impairs ipsilateral whisking. (A) An example of whisking bout following an electrolytic lesion. In $B$ all lesion sites were mapped onto a three-dimensional reconstruction of the medulla and selected anatomical substructures. The lesion centroids are denoted with symbols, with circles for electrolytic lesions, triangles for lesion via transport of Sindbis virus, and squares for chemical lesion by ibotenic acid. Injection of the glutamate channel agonist kainic acid activates the vIRt, which drives facial motoneurons and induces whisking. $(C)$ Vibrissa motion (blue), breathing (red), and intrinsic (green) EMG. (D) A polar plot of the coherence between spiking activity and vibrissa motion at the peak frequency of whisking. Open circles represent multiunit activity and closed circles represent single units. The green bar represents the coherence of the EMG for the intrinsic muscle $(B)$ with vibrissa motion. (Inserts) Spiking activity of neuronal units in the vIRt (black) in relation to vibrissa motion (blue). (Adapted from Moore et al. 2013.) 

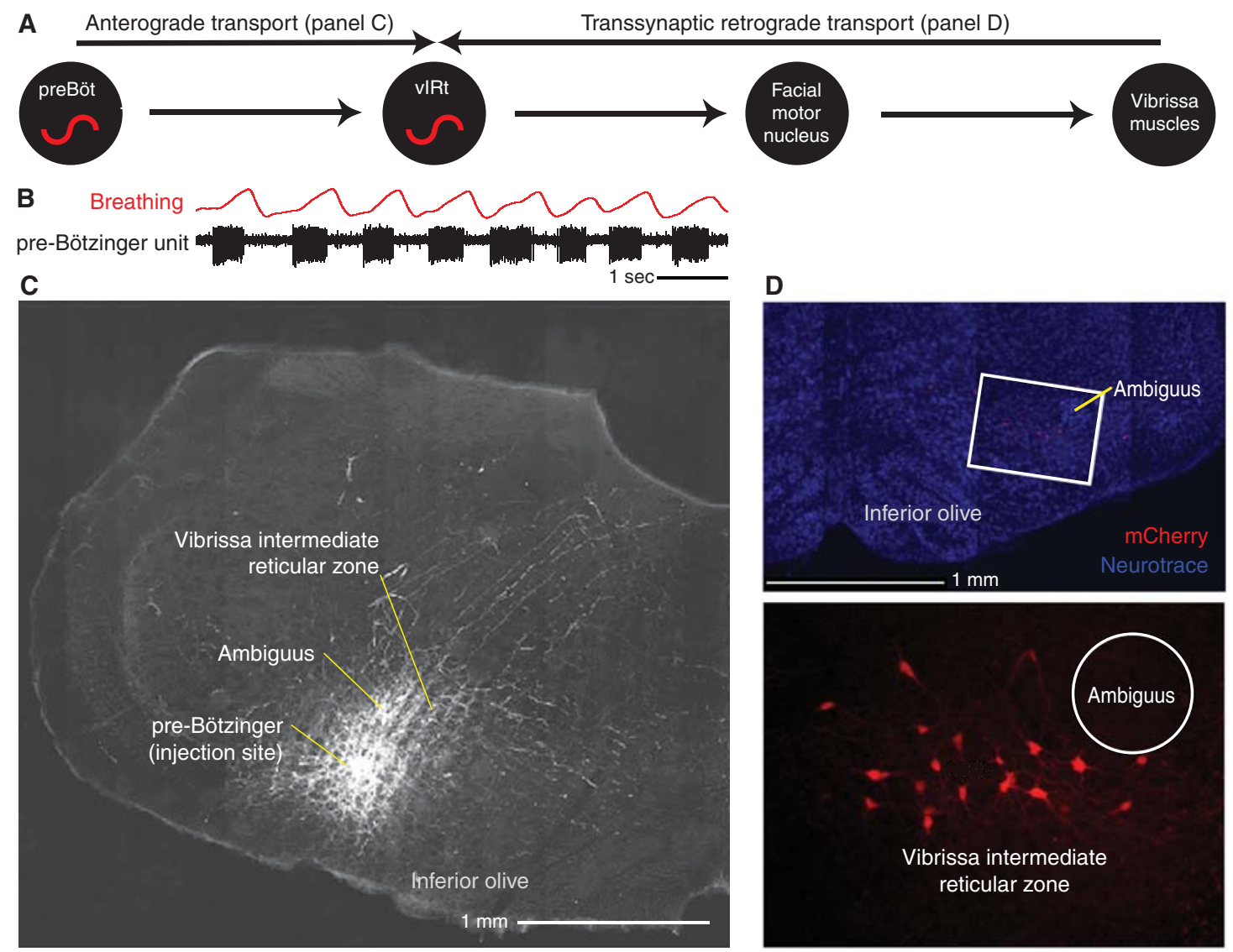

E
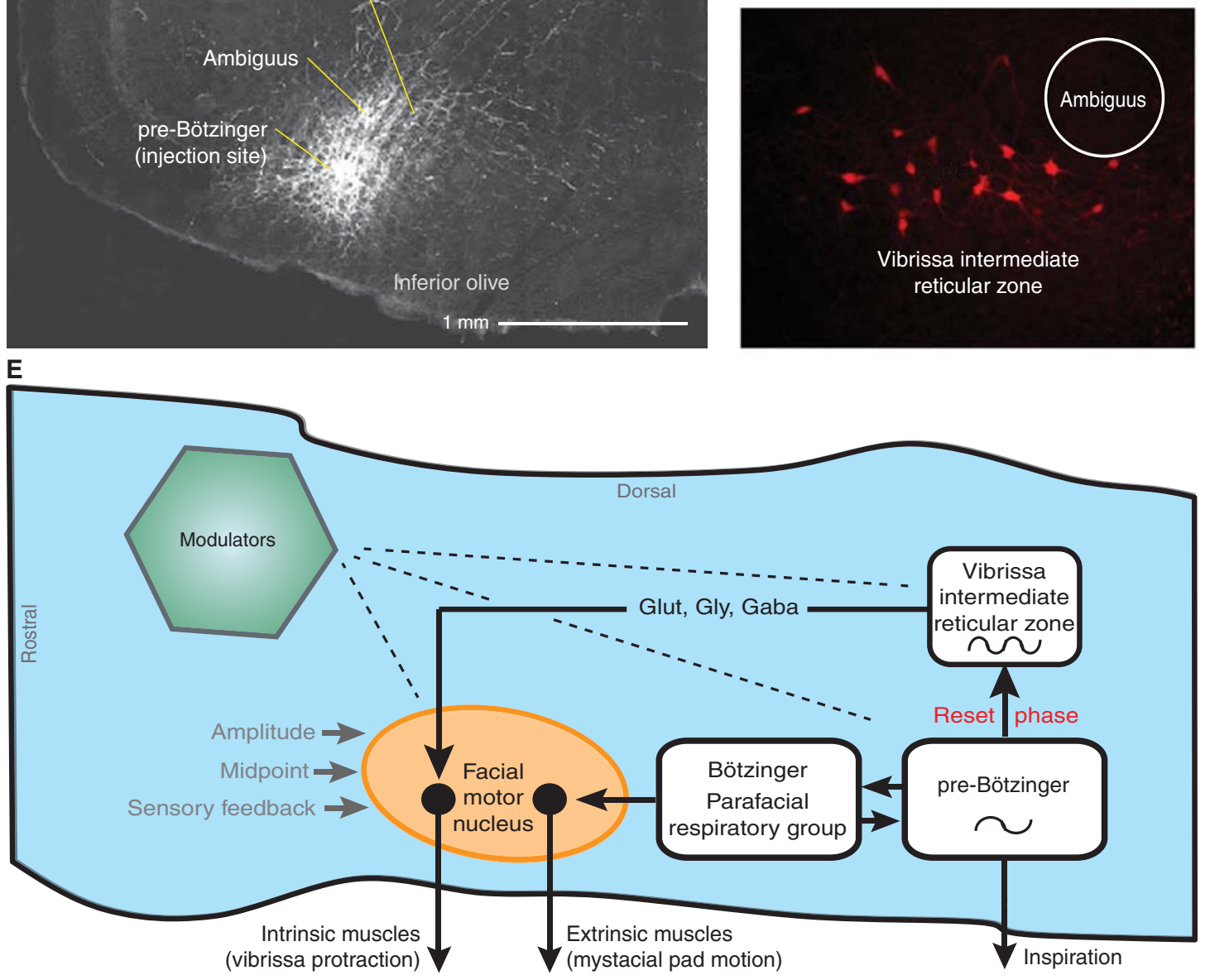

Figure 5. Anatomy and circuit for the resetting of whisking by breathing. (A) Proposed connectivity from the pre-Bötzinger complex, through the vIRt, and onward to the follicle muscles. Resolution of this connection pattern makes use of anterograde labeling to define the path from the pre-Bötzinger complex to the vIRt and retrograde transsynaptic labeling to define the pathway from the vIRt to the mystacial pad. $(B)$ Recording of a single inspiratory unit in the pre-Bötzinger complex, together with breathing. (Adapted from Moore et al. 2013.) (C) Tracing via injection of the anterograde tracer biotinylated dextran amine through the same pipette used to record $A$ leads to labeling of axons and terminals in the vIRt from cells in the pre-Bötzinger complex. (Adapted from Moore et al. 2013.) (D) Retrograde labeling of neurons in the vIRt by modified Rabies virus, $\Delta \mathrm{G}-\mathrm{RV}$, that was pressure injected into the facial musculature of juvenile transgenic mice engineered to express the glycoprotein under the premotor for choline acetyltransferase. Monosynaptically connected premotor neurons in the vIRt are labeled by $\Delta \mathrm{G}-\mathrm{RV}$ (red) and counterstained with Neurotrace fluorescent Nissl stain (Life Technologies) (blue). Ambiguus refers to nucleus ambiguus. (Adapted from Takatoh et al. 2013.) (E) Model of the circuitry that generates whisking that is coordinated with breathing. Dashed lines indicate diffuse synaptic input from modulatory brain nuclei. GLUT, glutamate; GLY, glycine; GABA, $\gamma$-aminobutyric acid. (Adapted from Moore et al. 2013.) 
connectivity from the breathing oscillator to the whisking oscillator, consistent with the reset of whisking by breathing but not vice versa (Moore et al. 2013).

We next delineated the projections from neurons in the vIRt to facial motoneurons. Here we used a retrograde scheme based on replication incompetent rabies virus to label from the muscles in the mystacial pad transynaptically back to the vIRt. A modified rabies virus, denoted $\Delta \mathrm{G}-\mathrm{RV}$, in which the gene for glycoprotein, $\mathrm{G}$, was deleted and the gene for red fluorescent protein inserted, was grown in cells engineered to produce G (Wickersham et al. 2007). This virus is injected into the facial musculature of juvenile transgenic mice that express $G$ in cholinergic neurons, so that infected motoneurons can recapitulate active rabies for subsequent labeling of premotoneurons. We observe strong labeling in the location of the vIRt (Fig. 5D; Takatoh et al. 2013). These and previous (Isokawa-Akesson and Komisaruk 1987) patterns of neuronal labeling in the IRt support a direct connection from the vIRt to the facial nucleus and substantiate the role of the vIRt as the premotor pattern generator for rhythmic whisking. In toto, the vIRt is an element of a larger circuit whereby cells in or near the pre-Bötzinger complex for inspiration (Tan et al. 2008; Bouvier et al. 2010; Gray et al. 2010) reset the phase of vIRt units with each breath during exploratory whisking (Fig. 5E).

Does the pathway found for the reset of whisking by breathing generalize to the coordination of other orofacial behaviors by breathing (Fig. 1)? From a purely anatomical basis, Feldman and colleagues (Tan et al. 2010) showed that neurons that are critical to the generation of the inspiratory rhythm in the pre-Bötzinger complex extend collateral projections across the ventral to dorsal extent of the IRt (Fig. 6A). These axons are likely to intersect the dendritic fields of premotor nuclei, like that of the vIRt for whisking, that drive other rhythmic orofacial actions (Fig. 6B). The best described of these is licking, for which tongue protrusions are coordinated with the respiratory cycle (Welzl and Bures 1977), and like whisking, may be controlled by a separate oscillator (Wiesenfeld et al. 1977). A cluster of hypoglossal premotoneurons is concentrated dorsomedial to the pre-Bötzinger complex within the IRt (Fig. 6B; Travers et al. 1997; Koizumi et al. 2008; Stanek et al. 2014). The spiking output of units in this region of the IRt locks to rhythmic licking (Travers et al. 2000), whereas infusion of an inhibitory agonist into the IRt blocks licking (Chen et al. 2001). These observations provide evidence in support of sufficiency and necessity, respectively, for these units as a premotor rhythm generator. Critically, hypoglossal premotoneurons produce bursts of spikes that are locked to inspiration (Ono et al. 1998). This evidence is therefore consistent with parallel premotor patterning circuits for licking and whisking in adjacent subcompartments of the IRt that are both influenced by breathing-related neurons in the pre-Bötzinger complex.

Beyond whisking and licking, the putative premotor oscillators for chewing (i.e., the oral portion of the IRt; Travers et al. 2005, 2010), for control of the airway (i.e., the ambiguus nucleus; Bieger and Hopkins 1987), and for licking (i.e., the hypoglossal IRt dorsomedial to the vIRt) are located proximally to each other (Travers et al. 1997) and to the pre-Bötzinger complex (Fig. 6B). All told, the existing results are consistent with a model in which preBötzinger units reset the onset of bursts in a network of hypoglossal premotor neurons in the IRt zone, and reset
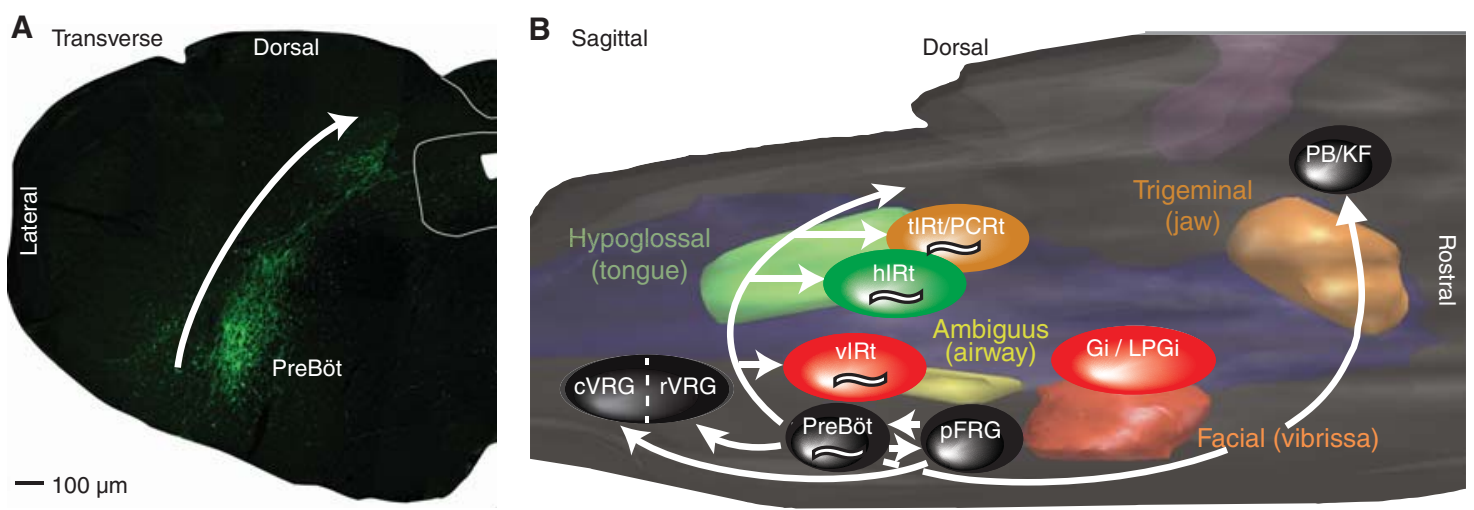

Figure 6. The pre-Bötzinger complex forms a "backplane" of collateral projections across the entire intermediate reticular zone. $(A)$ Injection of adeno-associated virus 2, which labels neurons by using the somatostatin promoter to drive the expression of enhanced green fluorescent protein (EGFP) (Tan et al. 2008), forms a band of EGFP-expressing axons along the intermediate reticular zone and revealed labeled axons in parahypoglossal nucleus/nucleus of the solitary tract regions (top) and ventral respiratory group caudal to pre-Bötzinger complex (bottom). No EGFP-expressing cell bodies were observed. (Adapted, with permission, from Tan et al. 2010, C Wiley.) (B) Three-dimensional reconstruction of the pons and medulla, showing the pools of cranial motoneurons that control the jaws (orange), face (red), airway (yellow), and tongue (green), as well as the approximate locations of known premotor nuclei to each of the motoneuron pools. Premotor nuclei are color coded according to the primary motor nucleus that they innervate. Breathing-related regions are shown in black, and the projections of the pre-Bötzinger complex are shown as white arrows. Putative rhythmic oscillators for whisking, licking, and chewing are denoted " ". cVRG, caudal ventral respiratory group; Gi, gigantocellular reticular formation; hIRt, hypoglossal intermediate reticular formation; LPGi, lateral paragigantocellular reticular formation; PCRt, parvocellular reticular formation; pFRG, parafacial respiratory group; PreBöt, pre-Bötzinger complex; rVRG, rostral ventral respiratory group; tIRt, trigeminal intermediate reticular formation; vIRt, vibrissa intermediate reticular formation. (Adapted from Moore et al. 2014b.) 
A

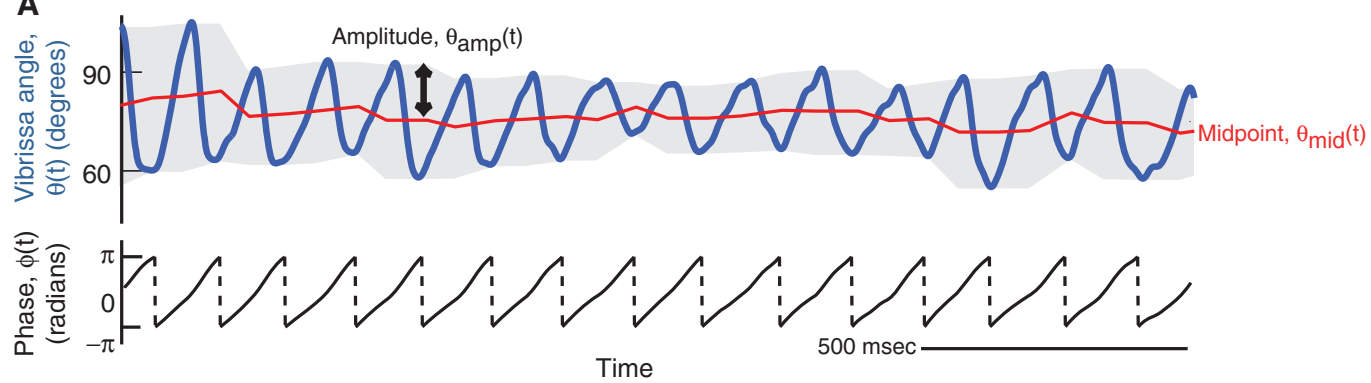

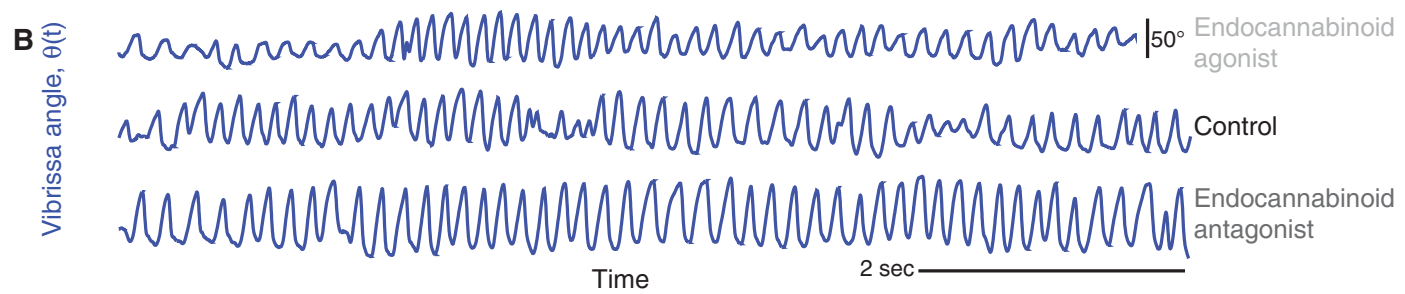

C

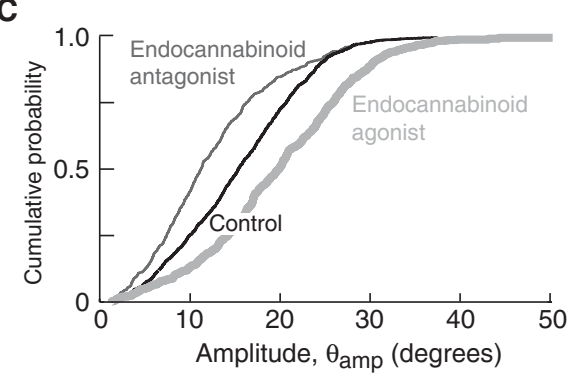

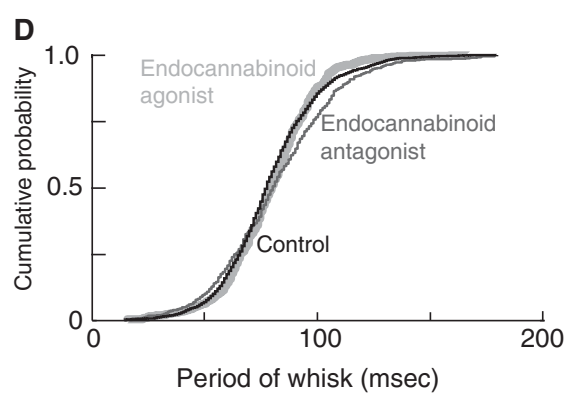

E

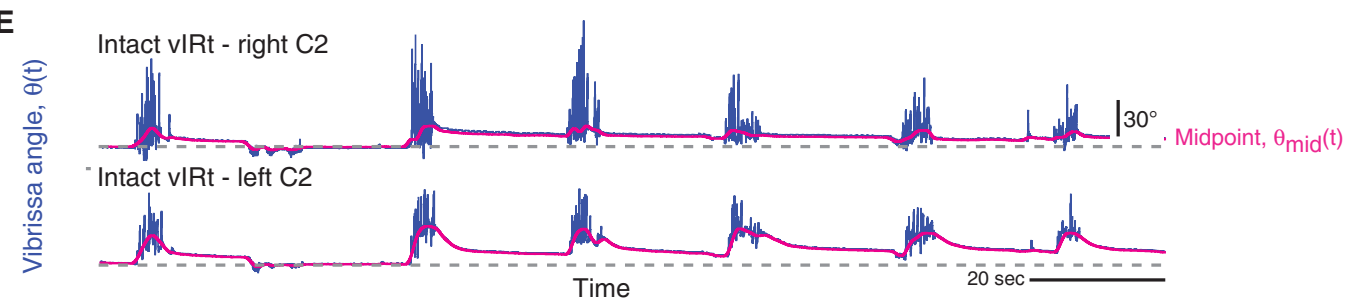

F

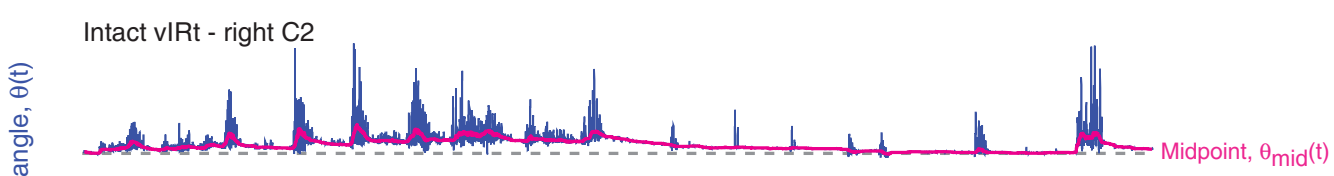

Lesioned left vIRt - left C2

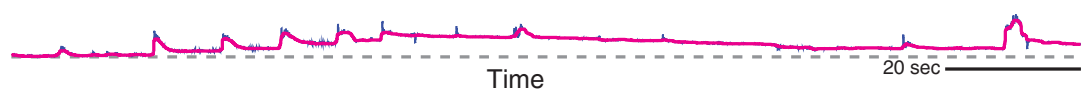

Figure 7. Evidence for the separation of slow processes (i.e., changes in amplitude and midpoint of whisking) from the fast rhythmic oscillation. (A) Decomposition of whisking into rapidly and slowly varying parameters via the Hilbert transform. Top panel shows vibrissa position along with its decomposition into the amplitude, $\theta_{\mathrm{amp}}$, and midpoint, $\theta_{\text {mid }}$, of the envelope (gray band). The lower trace shows the phase, $\phi$, along with broken vertical lines indicate wrapping of phase from $\pi$ to $-\pi$. (Adapted from Hill et al. 2011.) $(B-D)$ Effect of a cannabinoid receptor type 1 agonist and an antagonist on whisking amplitude but not frequency. $(B)$ Typical traces of vibrissa angle executed by an animal $4 \mathrm{~h}$ after administration of either $\Delta^{9}$-THC, an agonist (dark gray), vehicle (black), or SR141716A, an antagonist (light gray). Vertical calibration bar corresponds to $50^{\circ}$. $(C)$ The cumulative probability distribution function of protraction amplitudes across all animals; note the significant effect of agonists and antagonist. $(D)$ The cumulative probability distribution function of the period (inverse of frequency) of whisking across all animals; note the lack of a significant effect of agonists and antagonist. ( $B-D$, Adapted, with permission, from Pietr et al. 2010, (C) The American Physiological Society.) (E,F) Effect of lesioning the vIRt in one hemisphere (Fig. 4A,B) quenches rhythmic whisking yet does not interfere with changes in midpoint. In $E$, the midpoint of the motion (red) is seen to track between the two sides of the face. In $F$, lesion of the vIRt of the left side only prevents whisking on that side. Yet the midpoint of the vibrissae of the right and left side of the face continue to track each other. (New data obtained with the methods in Moore et al. 2013.) 
or otherwise influence the spiking of premotor neurons for other orofacial actions in parallel with our model of the circuit for whisking (Fig. 5E). Our ongoing work addresses the formation of behaviors through the coordinated integration of these disparate orofacial motor actions (Moore et al. 2014b).

We now step back and recall that rhythmic motor actions depend on the envelope of the rhythmic drive as well as the timing of the underlying oscillations. For the case of whisking, the envelope consists of a slowly varying amplitude, which may also gate the rhythm, and a slowly varying midpoint that sets the center of interest for exploratory whisks (Fig. 7A; Carvell et al. 1991; Berg and Kleinfeld 2003; Hill et al. 2008). A priori, the amplitude of whisking could be controlled by the vIRt or by a separate premotor nucleus that targets vibrissa motoneurons in the facial motor nucleus. The initial evidence for the latter possibility comes from a collaboration between the Ahissar and Vogel groups (Pietr et al. 2010), where it was shown that the normal variations in the amplitude of whisking are suppressed by systemic administration of an antagonist of the cannabinoid receptor but
A

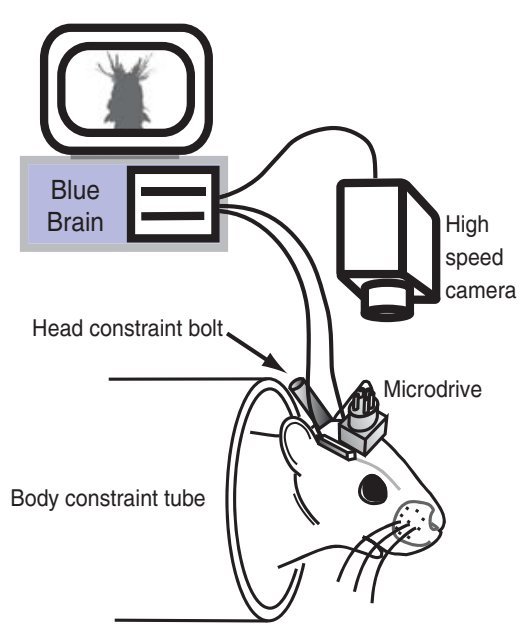

B
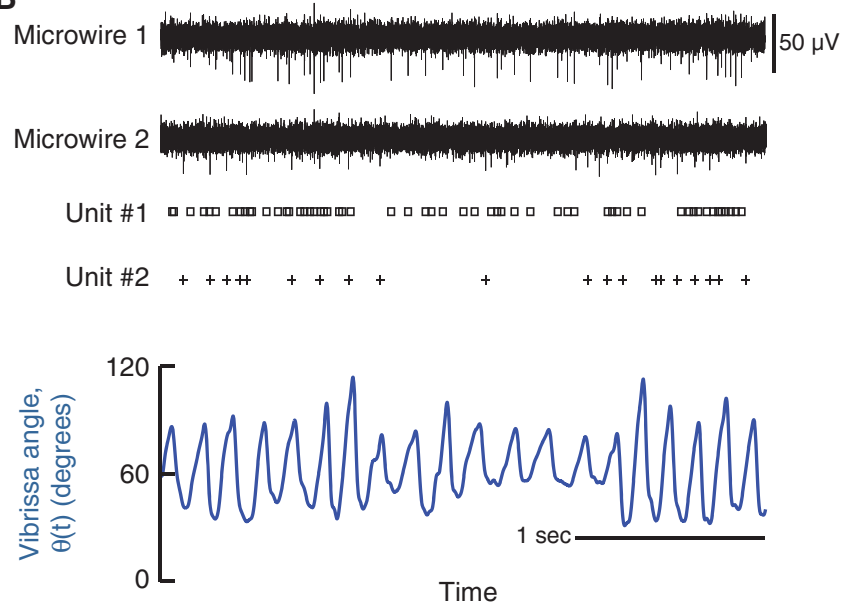

C
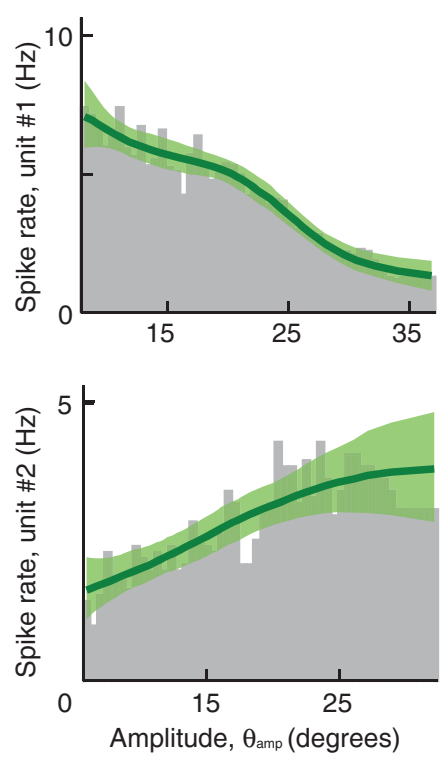
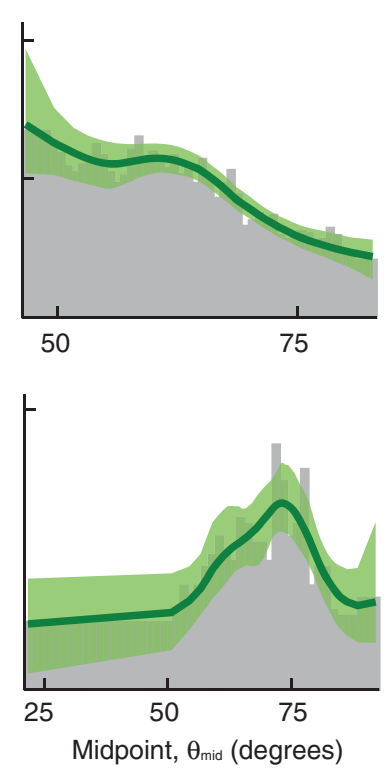

D
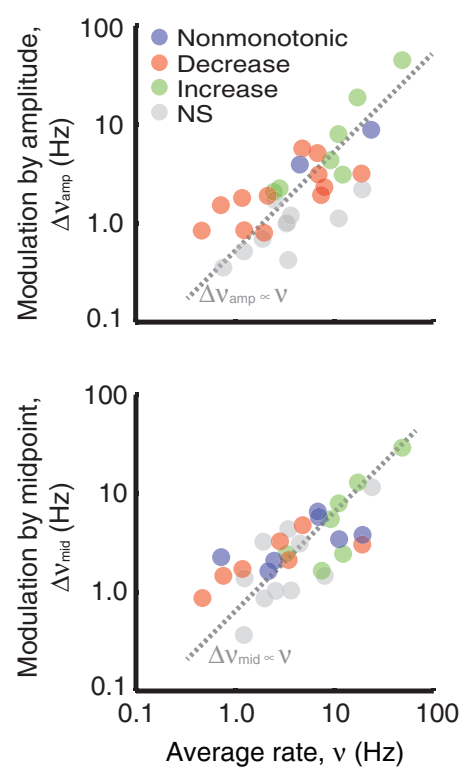

Figure 8. The vibrissa area of motor cortex codes the slowly varying midpoint and amplitude of whisking. $(A)$ The scheme used to measure the spiking activity of units in agranular motor cortex as body constrained animals rhythmically whisk in air. Vibrissa position is determined from videography. Single units, indicative of spiking by an individual neuron, are extracted from extracellular microwire recordings. $(B)$ Example records. $(C)$ Firing rate profiles for two example units as a function of amplitude and midpoint of vibrissa motion. The two rows are profiles of units that show different relative modulation. Each plot is calculated by dividing the distribution of the respective signal at spike time by the distribution of that signal over the entire behavioral session. Green lines are fits from a smoothing algorithm along with the $95 \%$ confidence band. $(D)$ Composite data across units illustrates that, on average, the rate is unaffected by whisking, consistent with the presence of units that both increase (green) and decrease (red) their rate with increasing angle. (Adapted from Hill et al. 2011.) 
heightened by an agonist (Fig. 7B,C). In contrast, there is no change in the frequency of the whisk cycle (Fig. $7 \mathrm{~B}, \mathrm{D})$. This result implies that the control of the slowly varying amplitude of whisking and the rapidly varying phase are independent, although the locus of the control of amplitude remains unknown.

The independence of the midpoint and the whisking rhythm was established by simultaneously monitoring the position of the vibrissae on both sides of the face before and after lesion of the vIRt in alert, head-restrained rats. In new data, we observe approximately synchronous motion of the midpoint between the right and left sides of the face during bouts of rhythmic whisking and stability of the midpoint between bouts (red lines in Fig. 7E). Lesioning the vIRt on one side abolished rhythmic whisking on that side, yet concurrent changes in the midpoint between the right and left sides of the face are maintained (Fig. 7F). This result implies the existence of a yet to be determined brainstem nucleus that controls slow changes in vibrissae position, potentially under the command of descending projections from other brain areas.

From a mathematical perspective, the independence of the slowly varying envelope of whisking from rapid changes in phase suggests that the angle of vibrissae relative to the face, $\theta(t)$, may be expressed as $\theta(t)=$ $\theta_{\mathrm{amp}}(t) \cdot \cos [\phi(t)]+\theta_{\text {mid }}(t)$ with $\mathrm{d} \phi(t) / \mathrm{d} t=2 \pi f_{\text {whisk }}$, where $f_{\text {whisk }}$ is the instantaneous whisking frequency (Hill et al. 2011), and $\theta_{\text {amp }}(t)$ and $\theta_{\text {mid }}(t)$ are the aforementioned slowly varying amplitude and midpoint parameters. How are these slowly varying parameters coded in the brain, and how do they influence the facial motoneurons that drive whisking? The first of these questions was examined by recording unit activity in agranular motor cortex (Brecht et al. 2004), concurrent with measurements of vibrissa position (Fig. 8A), as animals whisked in air (Fig. 8B; Hill et al. 2011; Friedman et al. 2012). We observe that the firing patterns of neurons in motor cortex preferentially report the slowly varying amplitude and midpoint of a whisking bout (Fig. 8C). Across a population of neurons, the modulation is approximately linear in the basal spike rate, with both increases and decreases in rate across different units for the same change in the envelope of whisking (Fig. 8D). One possible explanation for how these signals may influence facial motoneurons, under current investigation, is that they act as commands that are relayed through trigeminal nuclei (Matthews et al. 2014) that further project to facial motor neurons (Pinganaud et al. 1999). It will be valuable to determine if similar neuronal coding applies to the cortical control of other orofacial actions (Sawczuk and Mosier 2001).

How does the motion of a "master clock" play out with cognition? Let us suppose, consistent with the anatomy and the case for whisking and most likely for licking, that the relatively tight spatial organization of orofacial oscillators in the intermediate reticular zone provides a means for their reset by breathing as well as their rapid interaction (Fig. 6A). Then every orofacial sense, be it touch through whisking, smell through sniffing, and taste and touch through licking, will have a common underlying temporal signature through breathing. Thus the breathing rhythm, in addition to its physiological role in homeostasis, may serve a perceptual role in the binding of orofacial sensory inputs that enter through the pons, medulla, and olfactory bulb. These sensory inputs converge at the level of the ventromedial prefrontal cortex (Kleinfeld et al. 2014), a site of decision-making (Rushworth et al. 2007) that presumably incorporates the convergence of evidence from multiple sensory streams. It will be of interest to determine if binding by the respiratory rhythm plays a role in the spiking patterns of units in this highorder brain region and whether these units influence motor output.

\section{ACKNOWLEDGMENTS}

Our research was funded by the Canadian Institutes of Health Research (grant MT-5877), the United States National Institutes of Health (grants NS058668, NS066664, NS047101, and NS077986), the United States National Science Foundation (grant PHY-1451026), and the USIsraeli Binational Science Foundation (grant 2003222).

\section{REFERENCES}

Berg RW, Kleinfeld D. 2003. Rhythmic whisking by rat: Retraction as well as protraction of the vibrissae is under active muscular control. $J$ Neurophysiol 89: 104-117.

Bieger D, Hopkins DA. 1987. Viscerotopic representation of the upper alimentary tract in the medulla oblongata in the rat: The nucleus ambiguus. J Comp Neurol 262: 546-562.

Bouvier J, Thoby-Brisson M, Renier N, Dubreuil V, Ericson J, Champagnat J, Pierani A, Chédotal A, Fortin G. 2010. Hindbrain interneurons and axon guidance signaling critical for breathing. Nat Neurosci 13: 1066-1074.

Brecht M, Krauss A, Muhammad S, Sinai-Esfahani L, Bellanca S, Margrie TW. 2004. Organization of rat vibrissa motor cortex and adjacent areas according to cytoarchitectonics, microstimulation, and intracellular stimulation of identified cells. $J$ Comp Neurol 479: 360-373.

Carvell GE, Simons DJ. 1990. Biometric analyses of vibrissal tactile discrimination in the rat. $J$ Neurosci 10: 2638-2648.

Carvell GE, Simons DJ, Lichtenstein SH, Bryant P. 1991. Electromyographic activity of mystacial pad musculature during whisking behavior in the rat. Somatosens Mot Res 8: 159164.

Chen Z, Travers SP, Travers JB. 2001. Muscimol infusions in the brain stem reticular formation reversibly block ingestion in the awake rat. Am J Physiol Regul Intergr Comp Physiol 280: R1085-R1094.

Deutsch D, Pietr M, Knutsen PM, Ahissar E, Schneidman E. 2012. Fast feedback in active sensing: Touch-induced changes to whisker-object interaction. PLOS ONE 7: e44272.

Dörfl J. 1982. The musculature of the mystacial vibrissae of the white mouse. J Anat 135: 147-154.

Friedman WA, Zeigler HP, Keller A. 2012. Vibrissae motor cortex unit activity during whisking. J Neurophysiol 107: $551-563$.

Gao P, Bermejo R, Zeigler HP. 2001. Vibrissa deafferentation and rodent whisking patterns: Behavioral evidence for a central pattern generator. J Neurosci 21: 5374-5380.

Getting PA. 1989. Emerging principles governing the operation of neural networks. Annu Rev Neurosci 12: 185-204.

Gray PA, Hayes JA, Ling GY, Llona I, Tupal S, Picardo MC, Ross SE, Hirata T, Corbin JG, Eugenín J, et al. 2010. Developmental origin of preBötzinger complex respiratory neurons. J Neurosci 30: 14883-14895. 
Haidarliu S, Simony E, Golomb D, Ahissar E. 2010. Muscle architecture in the mystacial pad of the rat. Anat Rec (Hoboken) 293: 1192-1206.

Haidarliu S, Golomb D, Kleinfeld D, Ahissar E. 2012. Dorsorostral snout muscles in the rat subserve coordinated movement for whisking and sniffing. Anat Rec (Hoboken) 295: 1181-1191.

Hill DN, Bermejo R, Zeigler HP, Kleinfeld D. 2008. Biomechanics of the vibrissa motor plant in rat: Rhythmic whisking consists of triphasic neuromuscular activity. J Neurosci 28: 3438-3455.

Hill DN, Curtis JC, Moore JD, Kleinfeld D. 2011. Primary motor cortex reports efferent control of vibrissa position on multiple timescales. Neuron 72: 344-356.

Isokawa-Akesson M, Komisaruk BR. 1987. Difference in projections to the lateral and medial facial nucleus: Anatomically separate pathways for rhythmical vibrissa movement in rats. Exp Brain Res 65: 385-398.

Kleinfeld D, Sompolinsky H. 1989. Associative network models for central pattern generators. In Methods in neuronal modeling: From synapses to networks (ed. Koch C, Segev I), pp. 195-246. MIT Press, Cambridge.

Kleinfeld D, Deschênes M, Wang F, Moore JD. 2014. More than a rhythm of life: Breathing as a binder of orofacial sensation. Nat Neuroci 15: 647-651.

Koizumi H, Wilson CG, Wong S, Yamanishi T, Koshiya N, Smith JC. 2008. Functional imaging, spatial reconstruction, and biophysical analysis of a respiratory motor circuit isolated in vitro. J Neurosci 28: 2353-2365.

Lawson EE, Richter DW, Czyzyk-Krzeska MF, Bischoff A, Rudesill RC. 1991. Respiratory neuronal activity during apnea and other breathing patterns induced by laryngeal stimulation. J Appl Physiol 70: 2742-2749.

Lovick TA. 1972. The behavioural repertoire of precollicular decerebrate rats. $J$ Physiol 226: 4P-6P.

Matthews DW, Deschênes M, Furuta T, Moore JD, Wang F, Karten HJ, Kleinfeld D. 2014. Feedback in the brainstem: An excitatory disynaptic pathway for control of whisking. $J$ Comp Neurol. doi: 10.1002/cne.23724.

Moore JD, Deschênes M, Furuta T, Huber D, Smear MC, Demers M, Kleinfeld D. 2013. Hierarchy of orofacial rhythms revealed through whisking and breathing. Nature 469: 53-57.

Moore JD, Deschênes M, Kurnikova A, Kleinfeld D. 2014a. Activation and measurement of free whisking in the lightly anesthetized rodent. Nat Protoc 9: 1792-1802.

Moore JD, Kleinfeld D, Wang F. 2014b. How the brainstem controls orofacial behaviors comprised of rhythmic actions. Trends Neurosci 37: 370-380.

Nguyen QT, Kleinfeld D. 2005. Positive feedback in a brainstem tactile sensorimotor loop. Neuron 45: 447-457.

Ono T, Ishiwata Y, Inaba N, Kuroda T, Nakamura Y. 1998. Modulation of the inspiratory-related activity of hypoglossal premotor neurons during ingestion and rejection in the decerebrate cat. J Neurophysiol 80: 48-58.

Pietr MD, Knutsen PM, Shore DI, Ahissar E, Vogel Z. 2010. Cannabinoids reveal separate controls for whisking amplitude and timing in rats. J Neurophysiol 104: 2532-2542.

Pinganaud G, Bernat I, Buisseret P, Buisseret-Delmas C. 1999. Trigeminal projections to hypoglossal and facial motor nuclei in the rat. J Comp Neurol 415: 91-104.

Ranade S, Hangya B, Kepecs A. 2013. Multiple modes of phase locking between sniffing and whisking during active exploration. $J$ Neurosci 33: 8250-8256.

Rushworth MF, Buckley MJ, Behrens TE, Walton WE, Bannerman DM. 2007. Functional organization of the medial frontal cortex. Curr Opin Neurobiol 17: 220-227.
Sawczuk A, Mosier KM. 2001. Neural control of tongue movement with respect to respiration and swallowing. Crit Rev Oral Biol Med 12: 18-37.

Semba K, Komisaruk BR. 1984. Neural substrates of two different rhythmical vibrissal movements in the rat. Neuroscience 12: 761-774.

Sherrey JH, Megirian D. 1977. State dependence of upper airway respiratory motoneurons: Functions of the cricothyroid and nasolabial muscles of the unanesthetized rat. Electroencephalogr Clin Neurophysiol 43: 218-228.

Simony E, Bagdasarian K, Herfst L, Brecht M, Ahissar E, Golomb D. 2010. Temporal and spatial characteristics of vibrissa responses to motor commands. J Neurosci 30: 89358952.

Smith JC, Ellenberger HH, Ballanyi K, Richter DW, Feldman JL. 1991. Pre-Bötzinger complex: A brainstem region that may generate respiratory rhythm in mammals. Science 254: $726-729$.

Smith JC, Abdala APL, Rybak IA, Paton JFR. 2009. Structural and functional architecture of respiratory networks in the mammalian brainstem. Philos Trans R Soc Lond B Biol Sci 364: $2577-2587$.

Stanek E IV, Cheng S, Takatoh J, Han BX, Wang F. 2014. Monosynaptic premotor circuit tracing reveals neural substrates for oro-motor coordination. Elife 3: e02511.

Takatoh J, Nelson A, Zhou X, Bolton MM, Ehlers MD, Arenkiel BR, Mooney R, Wang F. 2013. New modules are added to vibrissal premotor circuitry with the emergence of exploratory whisking. Neuron 77: 346-360.

Tan W, Janczewski WA, Yang P, Shao XM, Callaway EM, Feldman JL. 2008. Silencing preBötzinger complex somatostatinexpressing neurons induces persistent apnea in awake rat. Nat Neurosci 11: 538-540.

Tan W, Pagliardini S, Yang P, Janczewski WA, Feldman JL. 2010. Projections of preBötzinger complex neurons in adult rats. J Comp Neurol 18: 1862-1878.

Tinbergen N. 1951. The study of instinct. Oxford University Press.

Travers JB, Dinardo LA, Karimnamazi H. 1997. Motor and premotor mechanisms of licking. Neurosci Biobehav Rev 21: $631-647$.

Travers JB, DiNardo LA, Karimnamazi H. 2000. Medullary reticular formation activity during ingestion and rejection in the awake rat. Exp Brain Res 130: 78-92.

Travers JB, Yoo JE, Chandran R, Herman K, Travers SP. 2005. Neurotransmitter phenotypes of intermediate zone reticular formation projections to the motor trigeminal and hypoglossal nuclei in the rat. J Comp Neurol 488: 28-47.

Travers JB, Herman K, Travers SP. 2010. Supression of third ventricular NPY-elicited feeding following medullary reticular formation infusions of muscimol. Behav Neurosci 124: 225-233.

Weiss PA. 1941. Self-differentiation of the basic patterns of coordination. Williams \& Wilkins, Baltimore.

Welker WI. 1964. Analysis of sniffing of the albino rat. Behaviour 12: 223-244.

Welzl H, Bures J. 1977. Lick-synchronized breathing in rats. Physiol Behav 18: 751-753.

Wickersham IR, Finke S, Conzelmann KK, Callaway EM. 2007. Retrograde neuronal tracing with a deletion-mutant rabies virus. Nat Methods 4: 47-49.

Wiesenfeld Z, Halpern BP, Tapper DN. 1977. Licking behavior: Evidence of hypoglossal oscillator. Science 196: 11221124.

Wineski LE. 1985. Facial morphology and vibrissal movement in the golden hamster. J Morphol 183: 199-217. 


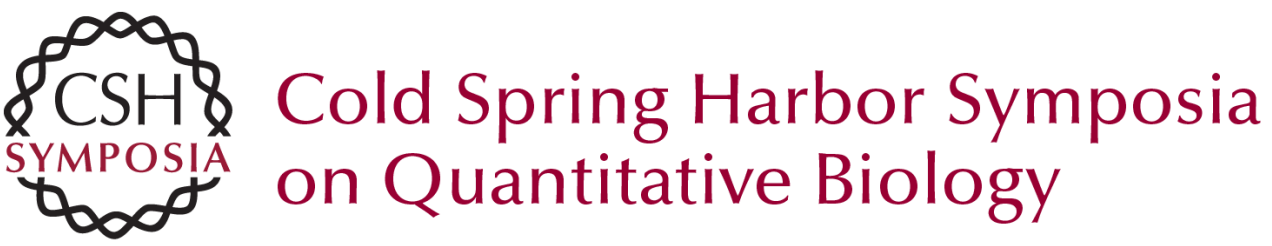

\section{The Brainstem Oscillator for Whisking and the Case for Breathing as the Master Clock for Orofacial Motor Actions}

David Kleinfeld, Jeffrey D. Moore, Fan Wang, et al.

Cold Spring Harb Symp Quant Biol 2014 79: 29-39 originally published online April 15, 2015 Access the most recent version at doi:10.1101/sqb.2014.79.024794

References This article cites 51 articles, 9 of which can be accessed free at: http://symposium.cshlp.org/content/79/29.full.html\#ref-list-1

License

Email Alerting Receive free email alerts when new articles cite this article - sign up in Service the box at the top right corner of the article or click here. 